\title{
Research and Application of 3G Electrical Safety Job Site Intelligent Monitoring Device
}

\author{
Changqing Zhao, Chenxu Zhao, Heng Xu, Haijun Zhang, Minghao Sun \\ The Bayannur power Bureau of Inner Mongolia Electric Power Group Co.Ltd, HuHeHaoTe, China \\ Email: bmzcx99@sina.com
}

Received February, 2013

\begin{abstract}
This paper describes the shortcomings and difficulties of power company security construction, such as site management for construction site security monitoring personnel is limited, in recent years, rural power grids and Urban Network alteration Faced with new situation. The use of advanced science and technology and communication terminal in order to better strengthen the means of power construction site safety supervision, improve the level of safety production supervision, design and development of a new electrical safety job site intelligent monitoring devices. The device consists of three parts of the remote wide angle 360 degrees of portable video surveillance equipment and 3G smart terminal equipment and portable battery. Through the application of such a device, professionals can remotely monitor the construction job site safety, diagnose, and effectively improve the security of the electricity sector management and reduce security risks and personnel on-site monitoring costs for improving the security of the entire power industry field operations with significance.
\end{abstract}

Keywords: Safety; Electrical; Intelligent Monitoring; Application

\section{Introduction}

As we all know, the personal safety of electric power construction site is the basic requirements for safe production. Part of the construction site, some of the work team, one-sided pursuit of speed of construction to the neglect of the safety management, the problem of illegal operations and inappropriate measures occur at any time, leaving many security risks, these problems have been plaguing the safety and production of electricity. Safety oversight becomes the focus of the work of production safety, only to strengthen the monitoring of security operations at the scene, in order to effectively control the occurrence of the accident. Monitoring of the power system is still generally the on-site supervision of security personnel and fixed within the scope of on-site monitoring, but most of the power construction work in the outdoors, mountains and pastoral areas and away from the city area, the safety of operations at the scene cannot be effective monitoring and protection. In order to ensure the personal safety of the construction site, the traditional methods of surveillance and security managers rely on on-site inspection, in recent years, supervision of rural power grids and city power grids due to limited manpower, has been unable to meet over a broad area of a new situation. Therefore, to strengthen the means of power construction site safety supervision is important. Improve the level of safety production supervision, is the first task placed the safety supervision department of the Power Supply Bureau. The events of a Power failure, some staffs lack of the technical level, rather than cannot quickly determine the point of failure. Not only affects the user a reliable power supply, and the extended outage time. Therefore, the necessary research and development of a mobile monitoring device, it can move with the job site and are subject to monitoring, so as to achieve effective control of field operations. With digital video compression, transmission, storage and playback as the core of a new generation of video surveillance system, this system is known as network digital video surveillance systems. The system has some of the advantages of the traditional monitoring system does not have, such as multi- functional, anti-jamming is strong, easy to maintain, easy to preserve. The digitization of information, networking and intelligent is a trend of social development, Therefore, the system for a mobile intelligent field operations monitoring devices, video compression and monitoring functions are concentrated into a small device, to provide reliable and uninterrupted power supply, Internet directly through the 3G network connection, plug and look to achieve on-site monitoring. Ensure scene safety operations thousands of miles away, you can also remotely monitor and viewing[1]. 


\section{3G Operations Monitoring Device Design}

\subsection{Technical Principle}

The monitoring device is the use of a remote wide angle of 360 degrees, portable video surveillance equipment, homemade tripod, portable battery providing battery composed of three parts. Through 3G communication module Remote transfer Audio, video surveillance terminal, it can enter the site to monitor construction to achieve a work-site monitoring equipment, all the data together to monitor the terminal, be adjusted by management implemented through the computer screen, a 360-degreepull into the wide-angle monitor with no blind spots, to achieve real-time supervision of distribution at various points of the multiple-site construction site.

\subsection{Technical Features}

The device produced by the current international stateof-the-art CCD camera monitoring equipment, it by microcomputer control the display of the host circulation or location to display the surveillance images, the use of Unicom's $3 G$ network to transmit. The device enables security managers in front of the computer terminal to monitor any construction site monitoring equipment, can also be monitored through intelligent mobile phone terminals, observed at any time to master the con-struction site of the security situation, especially the scene violation is found, can be promptly corrected to protect the construction site safety management. When the construction site, such as unplanned failures, have technical personnel and remote technical support, the construction site of the monitoring station can record important information as a future security. The device has the following characteristics:

1) High image quality. It can work in a situation complicated geographical conditions of the day and night, mountain, are able to ensure the image is clear, stable, true, in a timely manner to reflect the situation of the construction site.

2) Without cable restrictions. Transmission over 3G communication network, monitoring range, can any one point of view of 360-degree monitor the construction site, and simultaneous viewing of intelligent mobile terminals.

3) It is compact, easy to operate, easy to carry.

4) Electricity supply by the battery supply, in exceptional circumstances, then the vehicle power supply.

\subsection{Key Technology}

The performance of 3G mobile devices in the smart device is the key technology for device applications. $3 G$ key technologies mainly refer to the processor technology, RF technology, display technology, battery and power consumption, camera technology. Include the following technologies:[2]

1) Processor technologies to gradually adapt to the diversity of 3G terminals, high function and high quality development trends. 2) RF technology including the performance of the receiver and transmitter performance and antenna performance.3G RF characteristics of wide bandwidth, full duplex, zero-IF technology, multi-mode, etc. 3) 3G terminals in the average power consumption and $2 \mathrm{G}$ compared to a large increase, increased battery capacity requirements of $3 \mathrm{G}$ terminals.

\section{Use Characteristics}

\subsection{Work Efficiency of the Site}

Through the device, the safety supervision personnel to remote work site personnel arrangement layout, less than the site can propose a more reliable and reasonable job. Make the right judgments in the shortest possible time and to operate. Based on the distribution of "transparency" safety management, security management can always understand the state of the field staffs, such as checking the safety of field operations, check the security measures implemented, and staffs mental state are good. Full security operations under the supervision of staffs timely and accurate processing failure. Even if the staffs are not on the scene, and timely access to the system configuration of the wireless transmitter module fault information; device according to the system reflects the actual usage, and facilitate staff and reasonable arrangements for the relevant maintenance work.

\subsection{Device Used in Emergency Repair Work}

Monitoring by the monitoring device, after the emergency repairs and disaster (fire, earthquake, flood, etc.), some of the technical staff cannot come to the scene, the need for all professionals in consultation, the use of the device, and professionals through remote video terminals, the use of mobile phones through the 3G network monitoring to the site to construction site, to convene an expert consultation meeting. Effectively reduce the power-off time. Use the device through the job site, workers can be a short period of time to analyze the cause of the malfunction, graphic and video information sent wirelessly through the 3G network. Workers not on the scene can also understand the specific fault information, remote master site equipment failures caused by information, accurate and timely processing failure, effectively help to reduce power outage time and improve productivity[3].

\section{Domestic and International Research Profile}

In recent years, foreign countries already have some of 
the more mature wireless video-based server products, these products are generally side to complete video surveillance video capture and image compression and image network transfer functions. Such products in the domestic part of the company's own design and production, most of the monitoring systems use this program. Dedicated video server to network video surveillance, and basically meet the general monitoring requirements in the area, but all of the integrated system is relatively expensive. These products due to its own high price have hindered their use, such as some construction job site, and outdoor spaces. According to the research of related products at home and abroad, the use of $3 \mathrm{G}$ communications, mobile video surveillance have been success stories, but the monitor has been in power the job site is still blank, so the authors draw on the advanced methods used in the construction of power lines, power failure, repair the security scene technological innovation.

\section{Implementation Effect}

Use this device, the use of portable remote video monitoring equipment, with construction personnel entering the scene, and placed to the construction site safety supervision personnel remote to control the computer screen. Intelligent mobile terminal may use remote monitoring, real-time supervision of the distribution of multiple site construction site, both to reduce the intensity of the work safety supervision personnel, but also to strengthen the safety supervision, improve the work efficiency. Monitoring system put into use, the addition of a solid and reliable line of defense for job site safety management, leadership and safety supervision, remote real-time supervision of job site, to ensure the safety of the job site.
In particular in:

1) Monitoring devices can accurately record the job site a variety of behavior, you can reproduce the functions of the job site scenarios is complicated and more staffs on-site, you can repeat playback function, careful observation of each operating officer if there are violations.

2) The monitoring device can reduce the waste of human resources and can be achieved through the addition of the monitoring device to person more than one job site supervision.

\section{Applications}

The application of the device through the year, the timely control of job site conditions, to detect and deter the staffs violation; a substantial increase in the level of job site safety management, standardize the order of the job site, to eliminate the blank the status of illegal punishment. Security management can be realized from the office can be on the job site of the real-time security monitoring, reminded the safety of operations at any time, thereby reducing the staffs to go out the use of vehicle.

\section{REFERENCES}

[1] L. Sun (2011), "Preliminary study of the video surveillance of certain key technologies” Technology of Beijing University, Beijing, pp. 4-5.

[2] R. Billinton and P. Wang(1995), "A Generalized Method for Distribution System Reliability Evaluation,” IEEE WESCANEX'95 PROCEEDINGS, pp. 349-354

[3] Z. Z. Chen (2003), "Substation Remote Video Surveillance System, Industrial Control Applications,” Natural Science, 2001, pp. 48-51. 